\title{
pH değerleri farklı kahve türlerinde bekletilen kompozit rezinlerin yüzey pürüzlülüğünün değerlendirilmesi
}

\author{
Suzan Cangül(0000-0002-1546-7688) ${ }^{\alpha}$, Özkan Adıgüzel(0000-0001-6089-3013) ${ }^{\beta}$, Samet Tekin(0000-0001-8883-8307) \\ Faruk Öztekin(0000-0002-5131-0063) ${ }^{\lambda}$, Ömer Satıcı(0000-0002-5491-8138) ${ }^{\mu}$
}

Selcuk Dent J, 2020; 7: 252-258 (Doi: 10.15311/selcukdentj.515303)

Basvuru Tarihi: 20 Ocak 2019 Yayına Kabul Tarihi: 27 Ağustos 2019

\begin{abstract}
öz
pH değerleri farklı kahve türlerinde bekletilen kompozit rezinlerin yüzey pürüzlülüğünün değerlendirilmesi
\end{abstract}

Amaç: Bu çalışmanın amacı pH dereceleri farklı 5 kahve çeşidinin 4 farklı kompozit rezin üzerinde farklı periyodlarda oluşturduğu yüzey pürüzlülük miktarını değerlendirmektir.

Gereç ve yöntemler: Çalışmada her kompozit grubundan (Estelite Sigma Quick, G-Aenial, Clearfil Majesty, Ceram X One) 50 adet örnek hazırlandı. $2 \mathrm{~mm}$ derinliğinde $6 \mathrm{~mm}$ çapında eşit olarak hazırlanan disklere kompozit rezinler yerleştirildi. Her bir örnek polimerize edildi ve polisajları yapıldı. Deney öncesi örnekler 24 saat distile suda bekletildi ve profilometre cihazı kullanılarak ilk yüzey pürüzlülük değerleri kaydedildi. Her kompozit grubu 5 alt gruba ayrıldı. Sonrasında 1. gün, 2. gün ve 7. gün olacak şekilde kahvelerde (Nescafe, Türk kahvesi, Ethiopia, Colombia, Veranda) bekletilen örneklerin tekrar yüzey pürüzlülük ölçümleri yapıldı. Çalışmanın analizinde tek yönlü varyans analizi (ANOVA) ve Tamhane's T2 testleri (post hoc çoklu karşılaşııma testi) kullanıldı.

Bulgular: Kahvelerde bekletilen örneklerin 24 ve 48 saat sonundaki yüzey pürüzlülük sonuçlarının istatistiksel analizinde en fazla Ethiopia kahvesinde bekletilen Clearfil Majesty'de, en az ise Veranda kahvesinde bekletilen Estelite Sigma Quick rezininde pürüzlülük oluşmuştur. 7. gün sonunda ise Nescafede bekletilen Ceram $X$ One kompozit disklerinde oluşan yüzey pürüzlülüğü çok düşük değerlerde görülmüştür.

Sonuç: Sonuç olarak kompozit rezinlerin yüzey pürüzlülüğünde günlük tüketilen yiyecek ve içeceklerin sadece pH'sının değil, başka birçok faktörün de etkisi olduğu belirlenmiştir.

\section{ANAHTAR KELIMELER}

Kahve türleri, kompozit rezin, profilometre, yüzey pürüzlülüğü

Rezin bazı dental restoratif materyallerin kullanımı, iyi estetik özellikleri, uygulamalarının kolay olması ve diş sert dokularına bağlanabilmesi gibi olumlu özellikleri sebebiyle artmıştır. ${ }^{1}$ Restorasyonların uzun dönem klinik başarısını, kullanılan materyalin türü, yapısı,

\section{ABSTRACT}

Evaluation of the surface roughness of composite resins which are kept in coffee types in different $\mathrm{pH}$ grades

Background: The aim of this study is to evaluate the effect of immersion for different periods in 5 coffee types in different $\mathrm{pH}$ grades on the surface roughness of 4 different composite resins.

Methods: In the study, 50 samples were prepared from each composite group (Estelite Sigma Quick, G-Aenial, Clearfil Majesty, Ceram X One). Composite resins were placed in $2 \mathrm{~mm}$ deep, $6 \mathrm{~mm}$ diameter disc. Each sample was polymerized and polished. The samples were stored in distilled water for 24 hours and the initial surface roughness values were recorded using a profilometer. Each composite group was divided into 5 subgroups. Surface roughness measurements were then carried out on the samples immersed in the coffee (Nescafe, Turkish coffee, Ethiopia, Colombia, Veranda) on the 1st day, 2 nd day and 7 th day. One-way analysis of variance (ANOVA) and Tamhane's T2 tests (post hoc multiple comparison test) were used in the analysis of the study.

Results: The statistical analysis of the surface roughness results after 24 and 48 hours, revealed the highest roughness was in the Clearfil Majesty which was kept in the Ethiopia coffee and at lowest was in the Estelite Sigma Quick resin which was kept in the Veranda coffee. At the end of the 7th day, the roughness of the surface of Ceram X One composite discs which were immersed in Nescafe was found to be very low.

Conclusion: As a result, it has been determined that not only the $\mathrm{pH}$ but also many other factors related with the daily consumed food and beverages affect the surface roughness of composite resins.

\section{KEYWORDS}

Coffee types, composite resin, profilometer, surface roughness

aşınma ve bağlanma direnci, yüzey pürüzlülüğü, materyalin su emilimi ve suda çözünürlüğü, estetik kalitesi ve diş-restorasyon arayüz bütünlüğü etkilemektedir. ${ }^{1,2}$

\footnotetext{
${ }^{\alpha}$ Dicle Üniversitesi, Diş Hekimliği Fakültesi, Restoratif Diş Tedavisi Anabilim Dalı, Diyarbakır, Türkiye

${ }^{\beta}$ Dicle Üniversitesi, Diş Hekimliği Fakültesi, Endodonti Anabilim Dalı, Diyarbakır, Türkiye

${ }^{\gamma}$ Fırat Üniversitesi, Diş Hekimliği Fakültesi, Protetik Diş Tedavisi Anabilim Dalı, Elazığ, Türkiye

${ }^{\lambda}$ Firat Üniversitesi, Diş Hekimliği Fakültesi, Endodonti Anabilim Dalı, Elazı̆̆, Türkiye

${ }^{\mu}$ Dicle Üniversitesi, Tıp Fakültesi, Biyoistatistik ve Tıbbi Bilişsim Anabilim Dalı, Diyarbakır, Türkiye
} 
Özellikle yüzey pürüzlülüğü bakterilerin tutunmasını etkileyen önemli faktörlerin başında gelmektedir. Yüzey özelliklerinin değişimi çürük oluşumunun, renk değişiminin ve periodontal sorunların oluşumuna sebep olmaktadır. Bu durumun tersine, kompozit rezinlerin yüzey pürüzlülüğünün az olması mikroorganizmaların rezin yüzeyine tutunmasını engellemektedir. ${ }^{3}$

Kompozit rezinlerin yüzey pürüzlülüğünü bileşimindeki monomerlerin tipi, doldurucuların şekli, boyutu ve polimerizasyonun derinliği etkilemektedir. Yüzey pürüzlülüğünün azaltıması, doldurucu partikül büyüklüğünün azaltılıp doldurucu miktarııı arttırıması ile sağlanmaktadır., ${ }^{4,5}$ Hasta açısından da rahatsızlık yaratan yüzey pürüzlülüğü değerleri $0,3 \mu$ m'lik artı̧̧ ile dil ucuyla farkedilebilmektedir. ${ }^{6} \mathrm{Bu}$ değerlerin $0,2 \mu$ m'yi geçmesi plak oluşumu ve bakteri adezyonu oluşma intimalini arttırmaktadır. ${ }^{7}$

Son zamanlarda kahve, sporcu içecekleri, yapay tatlandırıcılı meşrubatlar ve enerji içeceklerinin bileşimlerindeki asit içeriği ve bu içeceklerin yüksek miktarlarda tüketilmesi kompozit rezinlerin kimyasal, mekanik ve termal yapılarında bozulmalara sebep olmaktadır. $^{8}$ Uzun süre asidik gıdaların tüketimi diş sert dokularının yumuşamasına ve yüzey özelliklerinin değişmesine yol açmaktadır. ${ }^{5} \mathrm{Bu}$ sebeplerden dolayı iyi mekanik özelliklere sahip bir restoratif materyal arayışı bir dizi yeni kompozit rezinin geliştirilmesini sağlamıştır.

Özellikle estetik restorasyonlarda kullanılan bu kompozit rezinler; matriks yapısı, doldurucu partiküllerin miktarı, tipi ve büyüklüğüne göre farklılıklar gösterirler. Ayrıca inorganik doldurucuların özellikleri de rezinlerin yüzey düzgünlüğü üzerine doğrudan etkilidir. ${ }^{9}$ Nanoteknolojideki gelişmelerle birlikte bu problemlerin önüne geçmek amacıyla iyi cilalanabilen, doldurucu içeriği ve aşınma direnci yüksek kompozit rezinler üretilmeye başlanmıştır. ${ }^{10,11}$

Kompozit rezinlerde görülen ve yüzey pürüzlülüğüne sebep olan bir diğer faktör de restorasyon-diş arayüzünde mikroboşluk oluşmasıdır. Bu boşlukların oluşumuna, polimerizasyon büzülmesi, rezini uygulama yöntemi, mine ve dentinin yapısal özellikleri, kavitenin yeri ve oklüzyon gibi birçok farklı neden de yol açmaktadır. ${ }^{12}$ Restorasyonun başarısı ve hasta memnuniyeti açısından kompozit rezinlerin bitirme ve parlatma işlemlerinin yapılması son derece önemlidir. ${ }^{13,14}$
Bu çalışmanın amacı pH dereceleri farklı 5 kahve çeşidinin, 4 farklı kompozit rezin üzerinde oluşturduğu yüzey pürüzlülüğü miktarını değerlendirmektir.

\section{GEREÇ VE YÖNTEM}

Bu çalışmada farklı kahve türlerinde bekletilen kompozit rezinlerin yüzey pürüzlülük değerleri incelenmiştir. Kompozit örnekleri aynı renklerde seçilmiş olmakla beraber içerikleri ve üretici firmaları Tablo 1'de belirtilmiştir.

\section{Tablo 1.}

\section{Kompozit türlerinin bileşimleri ve üretici firmaları}

\begin{tabular}{|c|c|c|c|}
\hline$\frac{\text { Kompozit }}{\text { Türleri }}$ & Bileşimleri & $\begin{array}{l}\text { Kompozit } \\
\text { Türü }\end{array}$ & Üretici Firma \\
\hline $\begin{array}{l}\text { Estelite } \\
\text { Sigma } \\
\text { Quick }\end{array}$ & $\begin{array}{l}\text { Bis-GMA, Trietyline glikol } \\
\text { dimetakrilat, silika-zirkonyum }\end{array}$ & $\begin{array}{l}\text { Supra-nano } \\
\text { Hibrit } \\
\text { Kompozit }\end{array}$ & $\begin{array}{l}\text { Tokuyama } \\
\text { (Tokyo/Japonya) }\end{array}$ \\
\hline G-Aenial & $\begin{array}{l}\text { Silica, Strontium and Lanthanoid } \\
\text { Fluoride containing, Fumed silica, } \\
\text { Urethane dimethacrylate (UDMA), } \\
\text { dimethacrylate co-monomers }\end{array}$ & $\begin{array}{l}\text { MFR Hibrit } \\
\text { Kompozit }\end{array}$ & $\begin{array}{l}\text { GC } \\
\text { (Tokyo/Japonya) }\end{array}$ \\
\hline $\begin{array}{l}\text { Clearfil } \\
\text { Majesty } \\
\text { Esthetic }\end{array}$ & $\begin{array}{l}\text { Silanlanmış baryum cam tozu, } \\
\text { silanlanmış koloidal silis, Bis- } \\
\text { pHenol A diglycidylmethacrylate } \\
\text { (Bis-GMA), Hidrofobik aromatik } \\
\text { dimethacrylate, di- } \\
\text { CompHorquinone }\end{array}$ & $\begin{array}{l}\text { Nano-hibrit } \\
\text { Kompozit }\end{array}$ & $\begin{array}{l}\text { Kuraray } \\
\text { (Tokyo/Japonya) }\end{array}$ \\
\hline $\begin{array}{l}\text { Ceram X } \\
\text { One } \\
\text { Universal }\end{array}$ & $\begin{array}{l}\text { Organik olarak modifiye edilmiş } \\
\text { seramik nano partiküller, } \\
\text { nanodoldurucular, konvansiyonel } \\
\text { cam doldurucular }\end{array}$ & $\begin{array}{l}\text { Nano } \\
\text { Seramik } \\
\text { Kompozit }\end{array}$ & $\begin{array}{l}\text { Dentsply } \\
\text { (Konstanz/Almanya) }\end{array}$ \\
\hline
\end{tabular}

Çalışmada her kompozit grubundan 5 alt grup oluşturulacak şekilde $(n=10) 50$ adet örnek hazırlandı. $2 \mathrm{~mm}$ derinliğinde ve 6 $\mathrm{mm}$ çapında disklere dört grup kompozit rezin sırasıyla yerleştirildi. Örneklerin yüzeylerinin düzgün olması amacıyla şeffaf bant ve siman camıyla baskı uygulandı. Böylelikle fazla materyalin taşması da sağlanmış oldu. Her bir örnek toplam 40 sn kadar LED ışık kaynağı (Woodpecker LED-B Curing Light, Guangxi, Çin) ile polimerize edildi. Daha sonra Sof-lex diskler (3M ESPE, St. Paul, $M N, A B D)$ kullanılarak tüm örneklerin polisajları yapıldı. Böylelikle pürüzsüz yüzeyler elde edilmiş oldu. Deney öncesi örnekler 24 saat distile suda bekletildi. Sonrasında profilometre cihazı (Surtronic 25, Taylor Hob- son, Leicester, İngiltere) kullanılarak ilk yüzey pürüzlülük değerleri kaydedildi ve bu değer Ra olarak belirlendi. Bu cihazın ölçüm aralığı $100 \mu \mathrm{m}$, değerlendirme uzunluğu $1.25 \mathrm{~mm}$, kesme uzunluğu $0.25 \mathrm{~mm}$ olarak kalibre edildi.

Daha sonra $\mathrm{pH}$ değerleri farklı 5 çeşit kahve, ölçüleri $2 \mathrm{ml}$ kahve/100 ml su olacak şekilde ayarlandı. Veranda (Veranda Blend), Colombia (Colombia Narino), Ethiopia (Moliendo) kahveleri hazırlanırken kahve presi belirtilen miktarda kaynamış sıcak su ile dolduruldu. Kahvenin tamamen presin alt tarafına çökmesi beklendi. Yaklaşık olarak $4 \mathrm{dk}$ demlendikten sonra demleme pistonu presin altına değene kadar yavaşça aşağıya doru itildi ve filtre kağıdından süzüldü. Nescafe (Nescafe Gold) verilen ölçülerde kaynamış suya koyularak karıştııılı, Türk kahvesi (Kuru Kahveci Mehmet Efendi) ise aynı ölçülerde kaynatılarak hazırlandı. Daha sonra standart bir ölçüm yapılabilmesi amacıyla sıcaklıklar $37^{\circ} \mathrm{C}$ 'de sabitlendi. Kahve türlerinin pH değerleri Tablo 2'de belirtilmiştir. 
Tablo 2.

\section{Kahve çeşitlerinin pH değerleri ve kullanım miktarları}

\begin{tabular}{|lcc|}
\hline $\begin{array}{l}\text { Kahve Türleri Ve Ticari } \\
\text { Adları }\end{array}$ & Kullanım Miktarları & $\begin{array}{c}\text { pH } \\
\text { Değerleri }\end{array}$ \\
\hline Nescafe (Nescafe Gold) & $2 \mathrm{ml}$ kahve/100 ml su & 5.00 \\
\hline Colombia (Colombia Narino) & $2 \mathrm{ml}$ kahve/100 ml su & 5.42 \\
\hline Ethiopia (Moliendo) & $2 \mathrm{ml}$ kahve/100 ml su & 5.56 \\
\hline Veranda (Veranda Blend) & $2 \mathrm{ml}$ kahve/100 ml su & 5.55 \\
\hline $\begin{array}{l}\text { Türk kahvesi (Kuru Kahveci } \\
\text { Mehmet Efendi) }\end{array}$ & $2 \mathrm{ml}$ kahve/100 ml su & 5.31 \\
\hline
\end{tabular}

Her kompozit grubu 10'arlı 5 alt gruba ayrıldı. Sonrasında 1 gün, 2 gün ve 7 gün olacak şekilde kahvelerde bekletilen örneklerin belirlenen süreler sonunda tekrar yüzey pürüzlülük ölçümleri yapıldı. Her örnekten 5 ölçüm yapıldı ve ortalama $\mathrm{Ra}$ değerleri kaydedildi. Kahvelerden ölçüm için çıkarılan örnekler öncelikle distile suyla yıkandı, kurutma kağıtlarıyla kurutuldu daha sonra ölçümleri yapıldı.

Tüm ölçümler sonrasında istatistiksel değerlendirmede $\mathrm{Ra}$ değeri kullanıldı. Elde edilen verilerin analizi SPSS 18.0 (SPSS Inc. Chicago, IL, ABD) programıla yapıldı. Belirlenen süreler sonundaki yüzey pürüzlülük karşıllaştırmalarında ise tek yönlü varyans analizi (ANOVA) ve post hoc çoklu karşıllaştırma testlerinden Tamhane's T2 testleri kullanıldı.

\section{BULGULAR}

Kompozit rezin örneklerinin yüzey pürüzlülük ölçümlerinin ilk istatistiksel değerlendirmesinde Clearfil Majesty diğer gruplara oranla daha fazla, G-Aenial ise daha az pürüzlülük değerleri göstermiştir (Tablo 3).

İlk ölçümlerden sonra kahvelerde bekletilen örneklerin 24 ve 48 saat sonundaki yüzey pürüzlülük sonuçlarının istatistiksel analizinde en fazla Ethiopia kahvesinde bekletilen Clearfil Majesty, en az ise Veranda kahvesinde bekletilen Estelite Sigma Quick rezininde pürüzlülük oluştuğu görülmüştür (Grafik 1, Grafik 2).
Tablo 3.

Kompozit rezinlerin yüzey pürüzlülük ortalama değerleri arasında istatistiksel olarak anlamlı farklılıklar vardır $(F=66,768 P=0,000)$

\begin{tabular}{|c|c|c|c|c|c|}
\hline & \multirow{2}{*}{$\begin{array}{l}\text { Örnek } \\
\text { Sayısı }\end{array}$} & \multirow{2}{*}{$\begin{array}{l}\text { Ortalama } \\
\text { değerler }\end{array}$} & \multirow{2}{*}{$\begin{array}{l}\text { Standart } \\
\text { sapma }\end{array}$} & \multicolumn{2}{|c|}{$95 \%$ güven aralığı } \\
\hline & & & & $\begin{array}{c}\text { En düşük } \\
\text { değer }\end{array}$ & $\begin{array}{c}\text { En yüksek } \\
\text { değer }\end{array}$ \\
\hline G-Aenial & 50 & 0,20622 & 0,120873 & 0,17187 & 0,24057 \\
\hline Clearfil Majesty & 50 & 0,60962 & 0,268628 & 0,53328 & 0,68596 \\
\hline Ceram X One & 50 & 0,48216 & 0,128576 & 0,44562 & 0,5187 \\
\hline Estelite Sigma Quick & 50 & 0,257 & 0,068685 & 0,23748 & 0,27652 \\
\hline Toplam & 200 & 0,38875 & 0,231905 & 0,35641 & 0,42109 \\
\hline
\end{tabular}

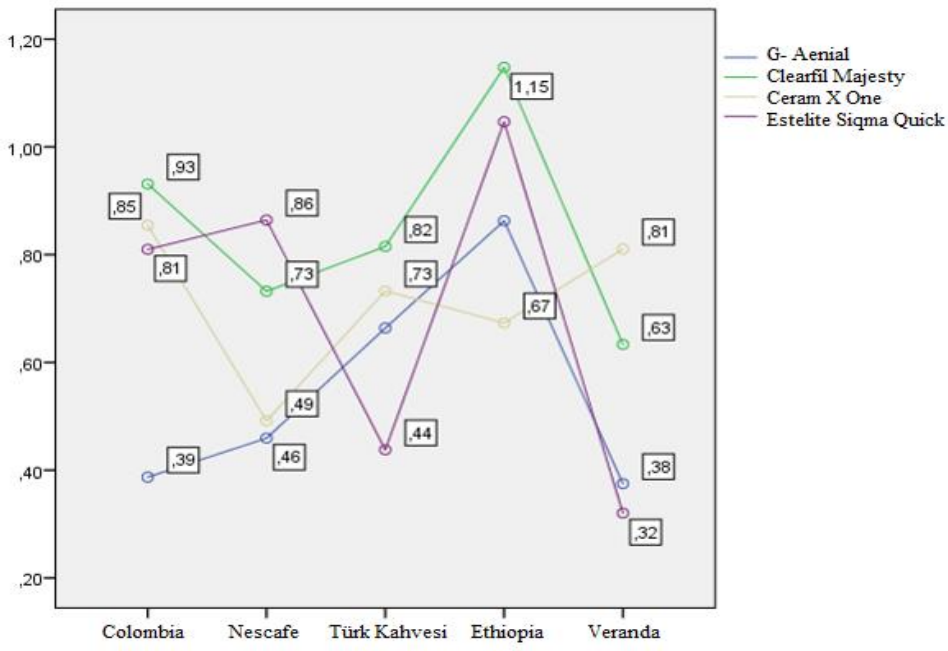

Grafik 1.

Kahvelerde bekletilen kompozit rezinlerin 24 saat sonundaki yüzey pürüzlülük değerleri

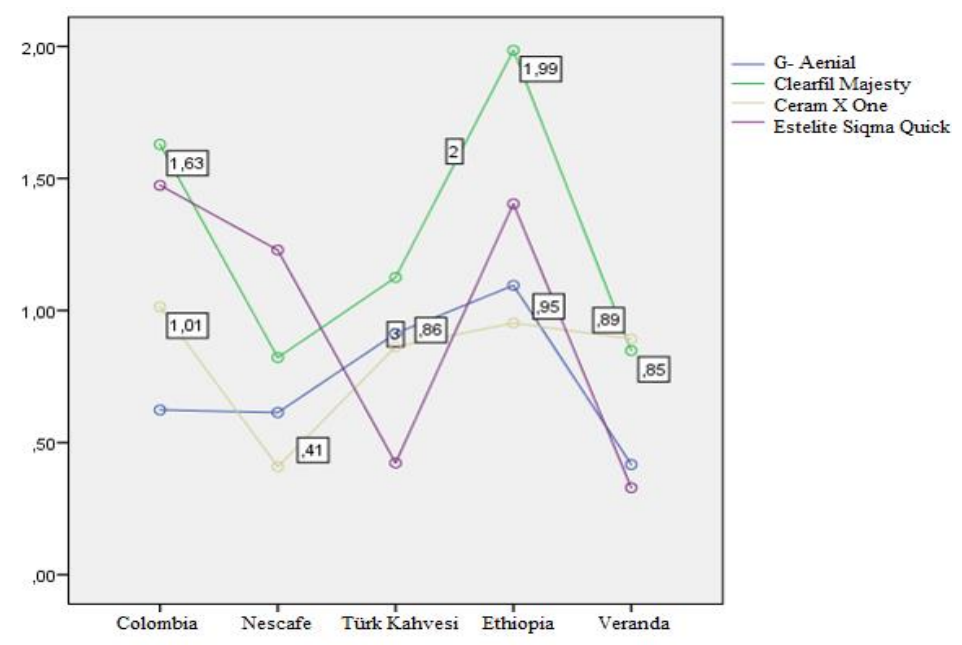

Grafik 2.

Kahvelerde bekletilen kompozit rezinlerin 48 saat sonundaki yüzey pürüzlülük değerleri 
7. gün sonundaki ölçüm sonuçlarına göre Ethiopia kahvesinde bekletilen Clearfil Majesty örneklerinde yüzey pürüzlülüğü daha fazla görülmüştür. Nescafede bekletilen Ceram X One kompozit disklerinde ise yüzey pürüzlülüğü diğer gruplara göre anlamlı düzeyde düşüktür (Grafik 3).

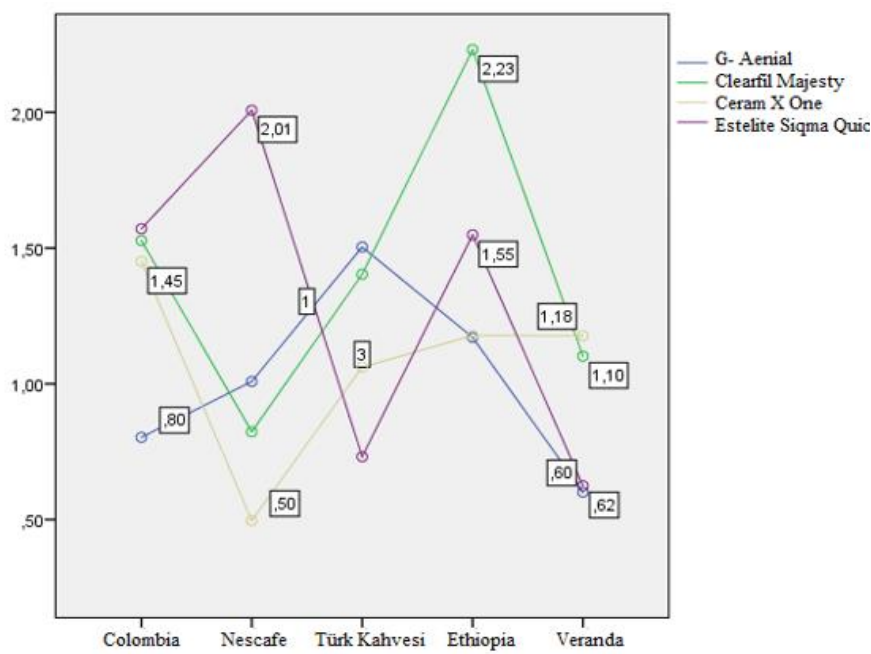

Grafik 3.

7. Gün sonunda kahvelerde bekletilen kompozit örneklerinin yüzey pürüzlülük ortalama değerleri

Bekletme sürelerinin etkisi ise bağımlı örneklem $t$ testi (paired student's $t$ testi) kullanılarak değerlendirildi. İstatistiksel olarak bekletme süreleri (1,2 ve 7 . gün) arasında anlamlı farklııklar olduğu görüldü (Tablo 4).

Tablo 4.

Bağımlı örneklem $t$ testi kullanılarak bekletme süreleri arasındaki farklılıkların değerlendirilmesi

\begin{tabular}{|c|c|c|c|c|c|}
\hline \multicolumn{6}{|c|}{ Bağımlı Örneklem İstatistikleri } \\
\hline Bağın & Örn. Student's t & Ortalama & $\begin{array}{l}\text { Örnek } \\
\text { Sayısı }\end{array}$ & $\begin{array}{l}\text { Standart } \\
\text { Sapma }\end{array}$ & Student's t \\
\hline \multirow{2}{*}{ Pair 1} & Yedinci Gün & 1,201 & 200 & 0,48441 & \multirow{2}{*}{$\begin{array}{c}t=11,68 \\
P=0,00 S\end{array}$} \\
\hline & II. Gün ölçümleri & 0,9504 & 200 & 0,45308 & \\
\hline \multirow{2}{*}{ Pair 1} & Yedinci Gün & 1,201 & 200 & 0,48441 & \multirow{2}{*}{$\begin{array}{c}t=20,04 \\
P=0,00 S\end{array}$} \\
\hline & I. Gün ölçümleri & 0,7025 & 200 & 0,24193 & \\
\hline \multirow{2}{*}{ Pair 2} & II. Gün ölçümleri & 0,9504 & 200 & 0,45308 & \multirow{2}{*}{$\begin{array}{c}t=12,30 \\
P=0,00 S\end{array}$} \\
\hline & I. Gün ölçümleri & 0,7025 & 200 & 0,24193 & \\
\hline
\end{tabular}

\section{TARTIŞMA}

Estetik gereksinimlerin artmasıyla beraber kompozit restorasyonlara talep de artmıştır. Uzun ömürlü restorasyonlar yapmak ve yapılan restorasyonun estetik görünümünü korumak için iyi bir bitirme ve parlatma işlemi yapmak gerekmektedir. Yapılan çalışmalar incelendiğinde pürüzlü yüzeyler çok daha fazla plak birikimine sebep olmaktadır. Bu çalışmada alüminyum oksit (Sof-lex) parlatma diskleri kullanılmıştır. Bu tekniğin, rezin yüzeylerinde düşük pürüzlülük elde etmenin en iyi yolu olduğu yapılan araştırmalarla açıklanmıştır. ${ }^{10}$

Yüzey pürüzlülüğü değerlendirmelerinde sıklıkla mikron düzeyde ölçüm yapabilen profilometre cihazı kullanılmaktadır. ${ }^{15}$ Bu cihaz Ra, Rz, Rmax, Rp, Rpm, Rt ve buna benzer birçok parametreyi hesaplayabilme özelliğine sahiptir. ${ }^{16}$ Yüzey pürüzlülüğü için kritik değer olan $0.2 \mu$ m'nin üstü durumlarda bakteri kolonizasyonu da artmaktadır. ${ }^{17}$ Biz de çalışmamızda kalitatif ölçüm yapabilen profilometre cihazını kullandık.

Kimyasal ve termal faktörler, kompozit rezinlerin uzun dönem klinik başarısını etkileyen etkenlerin başında gelmektedir. Özellikle kimyasal faktörler kompozit rezin yüzeylerinin bozulma sürecinde önemli rol oynamaktadır. ${ }^{18} \mathrm{Bu}$ süreçte oluşan kimyasal değişim, rezin yüzeylerinde pürüzlülüğe neden olmaktadır. ${ }^{19}$

Kompozit rezinlerin partikül büyüklüklükleri ve doldurucu içeriği gibi yapısal özellikleri yüzey pürüzlülüğünü direk olarak etkilemektedir. ${ }^{20,21}$ Doldurucu boyutlarının küçültülmesi ile cilalanabilirlikleri ve estetik özellikleri iyi rezin yüzeyleri elde edilir. ${ }^{22}$ Kompozit rezinlerin yapısına farklı büyüklükte doldurucu moleküllerin katılması ile bu özelliğin daha da iyileşmesi sağlanır. Yapılan çalışmalar büyük partiküller daha fazla yer kapladığından, aşınma esnasında küçük partiküllerin uzaklaşmasının yüzey özelliklerinin daha az değişmesini sağlayacağını açıklamışlardır. Bu amaçla kompozit rezin içerisinde boyutları farkı doldurucu moleküllerin kullanılması yüzey düzgünlüğü açısından çok önemlidir. Bazı araştııııılar da yüzey pürüzlülük değerlerindeki azalmayı doldurucu boyutundaki azalmayla ilişkilendirmişlerdir. ${ }^{22,23} \mathrm{Bu}$ sebeple çalışmamızda partikül büyüklükleri göz önüne alınarak nanohibrit ve mikrohibrit rezinler tercih edilmiştir.

Kahve, çay ve kola gibi bileşimlerinde asit içeren içeceklerin tüketimi kompozitlerin yüzey özelliklerini büyük ölçüde tehlikeye sokmaktadır. Çelik ve ark.'nın kahve, kola, distile su ve kırmızı şarap kullanarak kompozit rezinlerin yüzey 
pürüzlülüklerini değerlendirdikleri çalışmalarında kırmızı şarabın diğerlerine oranla daha fazla pürüzlülüğe sebep olduğu bildirilmiştir. ${ }^{24}$ Kolanın pH'ı diğerlerine oranla daha düşük olmasına rağmen kırmızı şarapta bekletilen örneklerin yüzeylerinde görülen pürüzlülük daha yüksektir. Kolalı içecekler ve kahve düşük pH'a sahip olmasının yanısıra eroziv potansiyeli arttırıcı karbonhidratlarla tatlandırılabilir, bu da yüzey pürüzlülüğünün artmasına yol açar. ${ }^{25,26}$

Karaman ve ark. benzer şekilde kompozitlerin farklı içeceklerdeki yüzey pürüzlülüklerini inceledikleri çalışmalarında distile su, kola ve kahvede bekletilen örneklerin pürüzlülük değerleri arasında anlamlı bir farklılık saptamamışlardır. Test edilen örneklerin ortalama değerleri 0.13 ile $0.09 \mu \mathrm{m}$ arasında değişmekle beraber plak birikimine sebep olan 0.2 um'lik kritik değerin altında kalmaktadır. ${ }^{27}$ Kitchens and Owens'in birkaç içeceğin eroziv etkisini inceledikleri çalışmalarında, kahvenin yüzey pürüzlülüğünü arttırdığı bildirilmiştir. ${ }^{28}$ Bizim çalışmamızda da, Nescafenin pH'sının diğer kahve türlerine göre daha düşük olmasına rağmen daha az yüzey pürüzlülüğüne neden olduğu görülmüştür. Sonuç olarak yapılan çalışmalar içeceklerin rezinler üzerinde oluşturduğu eroziv etkinin sadece pH'ya bağlı olmadığını, rezinlerin mineral yapılarının ve tamponlama kapasitelerinin de pürüzlülüğe neden olduğunu ortaya koymuştur. ${ }^{29,30}$

Bunların dışında su emilimi de yüzey özelliklerinde olumsuz değişimlere sebep olmaktadır. ${ }^{31,32} \mathrm{Su}$, kompozit rezinlerin organik matriks yapılarının bozulmasına ve yüzey sertliğinin azalmasına yol açmaktadır. Yapılan bir araştırmada, suyun metakrilat bazlı kompozit rezinlerin yüzeyinde değişimlere neden olduğu görülmüştür. ${ }^{33}$

\section{SONUÇ}

Sonuç olarak kompozit rezinlerin yüzey pürüzlülüğünde, günlük tüketilen yiyecek ve içeceklerin sadece pH'sının değil, başka birçok faktörün de etkisi olduğu belirlenmiştir. $\mathrm{Bu}$ nedenle rezinlerin özelliklerini olumsuz yönde etkileyebilecek durumların belirlenmesi açısından uzun dönem klinik çalışmaların yapılması daha aydınlatıcı sonuçların ortaya çıkmasını sağlayacaktır. 


\section{KAYNAKLAR}

1. Cangul $S$, Adiguzel $O$. The latest developments related to composite resins. Int Dent Res 2017; 7: 3241.

2. Spahl W, Budzikiewicz H, Geurtsen W. Determination of leachable components from four commercial dental composites by gas and liquid chromatography/mass spectrometry. J Dent 1998; 26: 37-45.

3. Lepri CP, Palma-Dibb RG. Surface roughness and color change of a composite: influence of beverages and brushing. Dent Mater J 2012; 31: 689-96.

4. Prakki A, Cilli R, Mondelli RFL, Kalachandra S, Pereira JC. Influence of $\mathrm{pH}$ environment on polymer based dental material properties. J Dent 2005; 33: 91-8.

5. Kakaboura A, Fragouli M, Rahiotis C, Silikas N. Evaluation of surface characteristics of dental composites using profilometry, scanning electron, atomic force microscopy and gloss-meter. J Mater Sci Mater Med 2007; 18: 155-63.

6. Yap AU, Mok BY. Effects of professionally applied topical fluorides on surface hardness of compositebased restoratives. Opere Dent 2002; 27: 576-81.

7. West NX, Maxwell A, Hughes JA, Parker DM, Newcombe RG, Addy M. A method to measure clinical erosion: the effect of orange juice consumption on erosion of enamel. J Dent 1998; 26: 329-35.

8. Pruthi G, Jain V, Kandpal HC, Mathur VP, Shah N. Effect of bleaching on color change and surface topography of composite restorations. Int J Dent 2010; 22: 1-7.

9. Buchalla W, Attin T, Hilgers RD, Hellwig E. The effect of water storage and light exposure on the color and translucency of a hybrid and a microfilled composite. J Prosthet Dent 2002; 87(3): 264-70.

10.Gonulol N, Yilmaz F. The effects of finishing and polishing techniques on surface roughness and color stability of nanocomposites. J Dent 2012; 40(2): 64-70.

11.Antonson SA, Yazici AR, Okte Z, Villalta P, Antonson $D E$, Hardigan PC. Effect of resealing on microleakage of resin composite restorations in relationship to margin design and composite type. Eur J Dent 2012; 6(4): 389-95.

12. Owens BM, Johnson WW. Effect of new generation surface sealants on the marginal permeability of Class $\mathrm{V}$ resin composite restorations. Oper Dent 2006; 31 (4): 481-8.

13.Ryba TM, Dun NWJ, Murchison DF. Surface roughness of various packable composites. Oper Dent 2003; 27: 243-7.

14.Arıcıoğlu B, Hatipoğlu Ö. Effects of surface treatments on the bond strength of glass hybrid restorative system repaired with hybrid composite resin. Int Dent Res 2018; 8(3): 131-8.

15. Bani M, Öztaş N. Cam iyonomer içerikli farklı restoratif materyallerin yüzey pürüzlülüklerinin değerlendirilmesi. Acta Odontologica Turcica 2013; 30: 13-7.
16. Barghi N, Alexander C. A new surface sealant for polishing composite resin restorations. Compend Contin Educ Dent 2003; 24: 30-3.

17. Erkli H, Ersöz E. Farklı fluor jellerin rezin materyallerin yüzey pürüzlülüğü üzerine etkisinin karşılaştırılması. Acta Odontol Turcica 2012; 29:7 9-85.

18. Yap AU, Wattanapayungkul $P$, Chung SM. Influence of the polymerization process on composite resistance to chemical degradation by food-simulating liquids. Oper Dent 2003; 28: 723-7.

19. Lee YK, Lu H, Oguri M, Powers JM. Changes in gloss after simulated generalized wear of composite resins. J Prosthet Dent 2005; 94: 3706.

20.Misilli U, Yılmaz F. Evaluation of marginal microleakage in composite restorations with different placement techniques. Int Dent Res 2018; 8(2): 70-7.

21.Türkün LŞ, Türkün $M$. Effect of bleaching and repolishing procedures on coffee and tea stain removal. J Esth Res Dent 2004; 16: 290-301.

22. Marghalani HY. Effect of filler particles on surface roughness of experimental composite series. J Appl Oral Sci 2010; 18: 59-67.

23. Cangül $S$, Adıgüzel Ö, Erpaçal $B$, Ünal $M$, Acartürk M, Satıcı Ö. Evaluation of shear bond strength of amalgam restorations repaired with composite resin by different surface treatments. Int Dent Res 2019; 9(3): 105-10.

24.Çelik N, Sağsöz Ö, Gündoğdu M. Farklı içeceklerin posterior kompozitlerin renk değişikliği ve yüzey pürüzlülüğü üzerine etkisinin değerlendirilmesi. Atatürk Üniv. Diş Hek. Fak. Derg. 2017; 27(1): 27-33.

25. Li H, Zou Y, Ding G. Dietary factors associated with dental erosion: a meta-analysis. PLoS One 2012; 7(8): 1-6.

26.von Fraunhofer JA, Rogers MW. Dissolution of dental enamel in soft drinks. Gen Dent 2004; 52(4): 308-12.

27. Karaman E, Tuncer D, Firat E, Ozdemir OS, Karahan S. Influence of Different Staining Beverages on Color Stability, Surface Roughness and Microhardness of Silorane and Methacrylate-based Composite Resins. J Contemp Dent Pract 2014; 15(3): 319-25.

28. Kitchens M, Owens BM. Effect of carbonated beverages, coffee, sports and high energy drinks, and bottled water on the in vitro erosion characteristics of dental enamel. J Clin Ped Dentist 2007; 31(3): 153-9.

29. Lussi A, Jaeggi T. Erosion-diagnosis and risk factors. Clin Oral Invest 2008; 12: 5-13. 
30.Isabel CAC, Domınguette AAS, Santos SG, Rıberro JCR, Moysés MR. Surface roughness of a resin composite. RGO- Revista Gaúcha de Odontologia 2016; $64: 50-5$.

31.Örtengren $\mathrm{U}$, Wellendorf $\mathrm{H}$, Karlsson S, Ruyter IE. Water sorption and solubility of dental composites and identification of monomers released in an aqueous environment. J Oral Reh 2001;28: 1106-15.

32.Turkun LS, Turkun M. The effect of one-step polishing system on the surface roughness of three esthetic resin composite materials. Oper Dent 2004; 29: 203-11.

33.Soderholm KJ. Degradation of glass filler in experimental composites. J Dent Res 1981; 11: 186775.

Yazışma Adresi:

Suzan CANGÜL

Dicle Üniversitesi Diş Hekimliği Fakültesi

Restoratif Diş Tedavisi AD

21280, Diyarbakır, Türkiye

Tel : : +904122411000/3363

GSM : +905301902198

E Posta: suzanbali@outlook.com 